\title{
ANALISIS KINERJA PENYULUH PERTANIAN DALAM MEMBERDAYAKAN DAN MEMANDIRIKAN PETANI PADI (Oryza Sativa) SAWAH DI KELURAHAN KEMPAS JAYA KECAMATAN KEMPAS KABUPATEN INDRAGIRI HILIR
}

\author{
Jalaluddin ${ }^{1}$, Gerhana Adjie ${ }^{2}$ \\ ${ }^{1}$ Program Studi Agribisnis, Universitas Lancang Kuning, Pekanbaru \\ ${ }^{2}$ STIE Indragiri, Rengat \\ Email: jalaluddinawang4@gmail.com (korespondensi)
}

\begin{abstract}
The Kempas District is one of the area that has the opportunity to develop food commodities, namely rice, especially wet rice. The rice productivity of Kempas District is higher than other districts in Indragiri Hilir Regency with a productivity yield of $39.96 \mathrm{kw} / \mathrm{ha}$ with an area of 2,300 ha. This study aimed to (1) determine the performance of agricultural instructors; (2) find out the level of farmer empowerment and farmer independence. This research was carried out in Kempas Jaya Village, Kempas District, Indragiri Hilir Regency for three months, October 2017 - December 2017. The type of data used in this study are primary data and secondary data. Primary data were obtained from interviews and questionnaires. Secondary data were obtained from information related to agricultural extension in Kempas District and online journals. The research method is quantitative through 30 rice farmers in Kempas Jaya District. Analysis of the data used in this study is descriptive analysis with a Likert scale. The results showed (1) the performance of extension workers in Kempas Jaya was "quite good" with a percentage of $73.3 \%$; (2) the level of empowerment of farmers in Kempas Jaya village is "very empowered" with a percentage of $60.0 \%$ and the independence of farmers in Kempas Jaya village is "Very Independent" with a percentage of $60.0 \%$.
\end{abstract}

Keywords: Extension, Farmers, Rice

\begin{abstract}
Abstrak
Kecamatan Kempas merupakan salah satu daerah yang memiliki peluang pengembangan komoditi pangan yaitu padi terutama padi sawah. Kecamatan Kempas memiliki produktivitas padi yang tinggi dibandingkan kecamatan yang lainnya di Kabupaten Indragiri Hilir dengan hasil produktivitas yang sebesar 39,96 kw/ha dengan luas lahan 2.300 ha. Penelitian ini bertujuan untuk (1) mengetahui kinerja penyuluh pertanian; (2) mengetahui tingkat keberdayaan petani dan kemandirian petani. Penelitian ini dilaksanakan di di Kelurahan Kempas Jaya Kecamatan Kempas Kabupaten Indragiri Hilir selama tiga bulan yakni Oktober 2017 - Desember 2017. Jenis data yang digunakan dalam penelitian ini adalah Data primer dan data sekunder. Data primer diperoleh dari wawancara dan kuesioner. Data sekunder diperoleh dari informasi terkait penyuluhan pertanian di Kecamatan Kempas dan jurnaljurnal online. Metode penelitian ini adalah kuantitatif terhadap 30 orang petani padi sawah di Kelurahan Kempas Jaya. Analisis data yang digunakan dalam penelitian ini adalah analisis dekskriptif dengan skala likert. Hasil penelitian menunjukkan (1) kinerja penyuluh di kelurahan Kempas Jaya adalah "cukup baik" dengan persentase 73,3\%; (2) tingkat keberdayaan petani di kelurahan Kempas Jaya adalah "sangat berdaya" dengan persentase $60,0 \%$ dan Kemandirian petani di kelurahan Kempas Jaya adalah "Sangat Mandiri" dengan persentase $60,0 \%$
\end{abstract}

Kata kunci: Penyuluh, Petani, Padi

1. PENDAhUlUAN

1.1 Latar Belakang
Pentingnya kinerja penyuluhan untuk meningkatkan pembangunan pertanian dan peningkatan pembangunan pertanian produksi pangan. Sesuai ketetapan pemerintah bahwa 
swasembada berkelanjutan padi sawah dicapai 3 tahun kedepan. Untuk mencapai target tersebut diterapkan upaya pola khusus (Upsus). Upsus adalah ikhtiar atau usaha bersama secara khusus untuk mencapai target yang telah ditetapkan melalui berbagai pemecahan masalah yang mungkin timbul dalam pencapaian target tersebut.

Tugas pokok dan fungsi yang tercakup dalam indikator kinerja penyuluh pertanian telah ditetapkan dalam Undang-Undang Nomor 16 Tahun 2006 Sistem Penyuluh Pertanian, Perikanan dan Kehutanan (Departemen Pertanian, 2010). Dalam menjalankan amanah UU-SP3K tersebut, terdapat banyak faktor yang berpengaruh terhadap kinerja penyuluh pertanian, baik berupa faktor personal maupun faktor situasional penyuluh. Faktor personal sebagai karakteristik penyuluh yang didasarkan pada latar belakang pendidikan, kemampuan, motivasi, masa kerja dan kepangkatan yang membentuk peribadinya, dan juga didasarkan pada faktor situasional yang mempengaruhi kinerja yakni program pelatihan dan dukungan sarana dan prasarana yang mendorong atau menghambat penyuluh untuk berkinerja baik.

Kecamatan Kempas merupakan salah satu daerah yang memiliki peluang pengembangan komoditi pangan yaitu padi terutama padi sawah. Kecamatan Kempas memiliki produktivitas padi yang tinggi dibandingkan kecamatan yang lainnya di Kabupaten Indragiri Hilir dengan hasil produktivitas yang sebesar $39,96 \mathrm{kw} / \mathrm{ha}$ dengan luas lahan 2.300 ha berdasarkan data dari Dinas Pertanian Indragiri Hilir tahun. Kecamatan Kempas dijadikan salah satu basis dipusatkan sebagai salah satu basis ketahanan pangan. Oleh karena itu daerah tersebut cukup baik untuk dikembangkan dan memegang peran penting dalam memenuhi kebutuhan pangan serta membuka lapangan pekerjaan bagi masyarakat petani. Kecamatan Kempas jumlah peyuluh sebanyak 15 orang dan 48 kelompok tani.

\section{TINJAUAN PUSTAKA}

\subsection{Penyuluhan Pertanian}

\subsubsection{Definisi Penyuluhan Pertanian}

Penyuluhan Pertanian adalah suatu upaya untuk terciptanya iklim yang kondusif guna membantu petani beserta keluarga agar dapat berkembang menjadi dinamis serta mampu untuk memperbaiki kehidupan dan penghidupannya dengan kekuatan sendiri dan pada akhirnya mampu menolong dirinya sendiri (Soeharto 2005). Pengertian penyuluhan dalam arti umum adalah ilmu sosial yang mempelajari sistem dan proses perubahan pada individu serta masyarakat agar dapat terwujud perubahan yang lebih baik sesuai dengan yang diharapkan.

\subsubsection{Sasaran Penyuluhan Pertanian}

Sasaran penyuluhan pertanian yaitu siapa yang sebenarnya disuluh atau ditujukan kepada siapa penyuluhan pertanian tersebut. Maka dengan tegas kita dapat menyatakan bahwa sasaran penyuluhan pertanian adalah para petani beserta keluarganya (Riyaningtyas, 2010).

\subsection{Kinerja Penyuluh Pertanian}

Kinerja berasal dari pengertian performance yang berarti hasil kerja atau prestasi kerja, namun kinerja mempunyai makna yang lebih luas, bukan hanya hasil kerja tetapi termasuk berlangsungnya proses pekerjaan. Kinerja adalah hasil pekerjaan yang mempunyai hubungan kuat dengan tujuan strategis organisasi, kepuasan konsumen, dan memberikan kontribusi pada ekonomi (Armstrong, 2004).

Faktor yang mempengaruhi pencapaian kinerja adalah faktor kemampuan (ability) dan faktor motivasi (motivation). Hal ini sesuai dengan pendapat Keith Davis dalam Mangkunegara (2010) yang merumuskan bahwa:

$$
\begin{array}{ll}
\text { Human Performance } & =\text { Ability }+ \text { Motivation } \\
\text { Motivation } & =\text { Attitude }+ \text { Situation } \\
\text { Ability } & =\text { Knowlage }+ \text { Skill }
\end{array}
$$

Sapar (2011), kinerja SDM dipengaruhi oleh tiga faktor, yaitu:

1. Faktor individu yang terdiri dari kemampuan dan keahlian, latar belakang dan demografi;

2. Faktor psikologis yang terdiri dari persepsi attitude, personality, pembelajaran, dan motivasi;

3. Faktor organisasi yang terdiri sumber daya, kepemimpinan, penghargaan, struktur dan job design.

Menurut Suhardiyono (1988), syarat-syarat yang harus ada dalam diri penyuluh pertanian adalah:

a. Kemampuan berkomunikasi dengan petani. Agar dapat berkomunikasi dengan petani, maka seorang penyuluh harus memiliki dasar-dasar pengetahuan praktik usahatani, dapat memahami bagaimana kehidupan petani, kemampuan mengenal orang desa, dan mau mendengarkan serta mau mengerti keluhan-keluhan yang disampaikan oleh mereka.

b. Kemampuan bergaul dengan orang lain. Agar dapat menyatu dengan petani, maka seorang penyuluh harus memiliki kemampuan untuk bergaul dengan orang lain.

c. Antusias terhadap tugasnya. Saat melaksanakan tugasnya, seorang penyuluh memerlukan tanggung jawab besar, karena sebagian besar waktunya dipergunakan untuk bekerja sendiri dengan bimbingan dan pengawasan yang sangat minim dan

d. Berpikir logis dan berinisiatif. Berpikir logis merupakan pengertian praktis yang harus dimiliki oleh seseorang, biasanya diperoleh 
dari pengalaman hidup, sedangkan inisiatif adalah kemampuan seseorang untuk melihat apakah ada suatu hal yang perlu dilakukan dan mempunyai keberanian untuk berusaha melakukan suatu hal tersebut tanpa perintah atau saran dari orang lain.

\subsection{Keberdayaan Petani}

Keberdayaan petani adalah dimilikinya daya, kekuatan atau kemampuan oleh petani untuk mengidentifikasi potensi dan masalah serta dapat menentukan alternatif pemecahannya secara mandiri. Keberdayaan petani diukur melalui tiga aspek (a) kemampuan dalam pengambilan keputusan, (b) kemandirian dan (c) kemampuan memanfaatkan usaha untuk masa depan. (Widjajanti, 2011).

Keberdayaan kelembagaan adalah keberdayaan sumber daya manusia dari konsep tridaya. Pratama (2015), ada empat kelembagaan yang mempelajari suatu kelembagaan yang mencakup aspek di luar dan di dalam kelembagan itu sendiri yaitu:

1. Kondisi lingkungan eksternal (the external environment). Merupakan suatu faktor pengaruh yang dapat menjadi pendorong dan sekaligus pembatas seberapa jauh suatu kelembagaan dapat beroperasi. Kondisi lingkungan tersebut adalah: kondisi politik dan pemerintahan (administration and external policies environment), teknologi (technological environment), kondisi perekonomian (economic environment).

2. Motivasi kelembagaan (institutional motivation). Empat aspek yang bisa dipelajari untuk mengetahui motivasi kelembagaan yaitu, sejarah kelembagaan tersebut (inatitutional history), misi yang diembannya, kultur yang menjadi pegangan dalam bersikap

3. dan berperilaku anggotanya, serta pola penghargaan yang dianut (incentive shemes) yang menyangkut sistem reward and punishment yang dianut suatu kelembagaan,

4. Kapasitas kelembagaan (institutional capacity), yang menyangkut bagaimana kemampuan kelembagaan untuk mencapai tujuannya sendiri yang diukur dari lima aspek yaitu: strategi kepemimpinan yang dipakai (strategic leadership), perencanaan program (program planning), manajemen dan pelaksanaannya (management and execution), alokasi sumber daya yang dimiliki (resources allocation), dan hubungan dengan pihak luar.

5. Kinerja kelembagaan (insititutional performance), kinerja kelembagaan merupakan kemampuan suatu kelembagaan untuk menggunakan sumber daya yang dimiliki secara efisien dan menghasilkan output yang sesuai dengan tujuannya dan relevan dengan kebutuhan pengguna. Tiga hal yang harus diperhatikan yaitu: keefektifan kelembagaan dalam mencapai tujuan-tujuannya, efisiensi penggunaan sumber daya, dan keberlanjutan kelembagaan berinteraksi dengan para kelompok kepentingan di luarnya.

\subsection{Kemandirian Petani}

Kemandirian adalah suatu konsep yang sering dihubungkan dengan pembangunan. Dalam konsep ini program-program pembangunan dirancang secara sistematis agar individu maupun masyarakat menjadi subyek dari pembangunan. Walaupun kemandirian sebagai filosofi pembangunan juga dianut oleh negara-negara yang telah maju secara ekonomi, tetapi konsep ini lebih banyak dihubungkan dengan pembangunan yang dilaksanakan oleh negara-negara sedang berkembang (Ismawan, 2003)

\subsection{Usaha Tani Padi Sawah}

Tingkat pendapatan petani secara umum dipengaruhi oleh beberapa komponen yaitu jumlah produksi,harga jual, dan biaya-biaya produksi Padi merupakan salah satu komoditi yang mempunyai prospek cerah guna menambah pendapatan para petani. Hal tersebut dapat memberi motivasi tersendiri bagi petani untuk lebih mengembangkan dan meningkatkan produksinya dengan harapan agar pada saat panen memperoleh hasil penjualan tinggi guna memenuhi kebutuhannya. Namun secara aktual pada saat panen tiba, hasil melimpah tetapi harga menjadi turun, dan terlebih lagi jika hasil produksi yang diharapkan jauh dari perkiraan, yaitu pembeli sangat rendah, produksi minim, biaya untuk kegiatan produksi, mulai dari pengadaan pupuk, pengolahan, pestisida dan biaya lainnya yang tidak terduga.

\section{HASIL DAN PEMBAHASAN}

\subsection{Keadaan Umum Daerah Penelitian}

Kelurahan Kempas Jaya adalah salah satu kelurahan yang terdapat di Kecamatan Kempas Kabupaten Indragiri Hilir Provinsi Riau. Luas wilayah Kelurahan Kempas Jaya yaitu 61,98 $\mathrm{Km} 2$.

a. Sebelah Utara dengan Kelurahan KaryaTunas Jaya Kecamatan Tempuling

b. Sebelah Selatan dengan Kecamatan Keritang

c. Sebelah Barat dengan Desa Bayas Jaya Kecamatan Kempas

d. Sebelah Timur dengan Kelurahan Harapan Tani Kecamatan Kempas

Keadaan tanahnya yang sebagian besar terdiri dari tanah gambut maka daerah ini digolongkan daerah beriklimm tropis basah dengan udara agak lembab. Pada Tahun 2017 curah hujan tertinggi di Kelurahan Kempas Jaya 
mencapai $281 \mathrm{~mm}$ terjadi di bulan Desember dengan hari hujan tertinggi terjadi di bulan yang sama yaitu 17 hari.

\subsection{Tingkat Kinerja Penyuluh Pertanian di Kecamatan Kempas}

Setelah data kinerja penyuluh didapatkan dari persebaran angket/kuesioner melalui petani kepada 30 orang respoden, Penentuan sampel penelitan dari petani diambil jumlah di Kelurahan Kempas Jaya sebanyak 30 orang dihitung tingkat kinerja penyuluh dan didapatkan hasil sebagai berikut:

Tabel 1. Kinerja Penyuluh Pertanian

\begin{tabular}{|c|c|c|c|c|}
\hline \multirow[b]{2}{*}{ No } & \multirow{2}{*}{$\begin{array}{l}\text { Kategori } \\
\text { Kinerja } \\
\text { Penyuluh }\end{array}$} & \multirow[b]{2}{*}{$\begin{array}{l}\text { Rentang } \\
\text { Skor }\end{array}$} & \multicolumn{2}{|c|}{ Jumlah } \\
\hline & & & $\begin{array}{l}\text { Freku } \\
\text { ensi }\end{array}$ & $\begin{array}{l}\text { Persent } \\
\text { ase } \\
(\%)\end{array}$ \\
\hline 1 & $\begin{array}{l}\text { Sangat Baik } \\
\text { (SB) }\end{array}$ & $4,20-5,00$ & - & - \\
\hline 2 & Baik (B) & $3,40-4,19$ & 3 & 10,0 \\
\hline 3 & $\begin{array}{l}\text { Cukup Baik } \\
\text { (CB) }\end{array}$ & $2,60-3,39$ & 22 & 73,3 \\
\hline 4 & $\begin{array}{l}\text { Kurang Baik } \\
\text { (KB) }\end{array}$ & $1,80-2,59$ & 5 & 16,7 \\
\hline 5 & $\begin{array}{l}\text { Sangat } \\
\text { Kurang Baik } \\
\text { (SKB) }\end{array}$ & $1,00-1,79$ & - & - \\
\hline \multicolumn{3}{|c|}{ Total } & 30 & 100 \\
\hline
\end{tabular}

Sumber: Data Olahan, 2018

Berdasarkan tabel 1 diketahui bahwa tingkat kinerja penyuluh adalah pada kategori "cukup baik" dengan persentase $73,3 \%$. Hasil ini menunjukkan bahwa kinerja penyuluh sepenuhnya belum optimal.

Menurut Bernardin \& Russel dalam Mardikanto (2009) tanpa adanya kinerja berarti tidak ada upaya untuk mencapai hasil atau target dan tidak akan terjadi suatu perubahan

Adapun berdasarkan penelitian yang telah dilakukan terkait dengan kinerja penyuluh pertanian di Kecamatan Kempas yang meliputi 3 indikator yaitu persiapan, pelaksanaan dan evaluasi penyuluhan maka diperoleh hasil sebagai berikut.

\subsection{Evaluasi dan pelaporan}

Pada penelitian ini, evaluasi dan pelaporam diukur berdasarkan dua indikator yaitu melakukan evaluasi pelaksanaan penyuluhan pertanian dan membuat laporan pelaksanaan penyuluhan pertanian. Maka dari hasil penelitian yang telah dilakukan di Kecamatan Kempas diperoleh hasil pada Tabel 18 sebagai berikut.

Tabel 2. Kinerja penyuluh pertanian Berdasarkan evaluasi dan pelaporan

\begin{tabular}{|c|c|c|c|}
\hline No & $\begin{array}{c}\text { Evaluasi dan } \\
\text { Pelaporan }\end{array}$ & Skor & Kategori \\
\hline
\end{tabular}

\begin{tabular}{|c|c|c|c|}
\hline 1 & $\begin{array}{c}\text { Melakukan evaluasi } \\
\text { pelaksanaan } \\
\text { penyuluhan }\end{array}$ & 2,70 & Cukup Baik \\
\hline 2 & $\begin{array}{c}\text { Membuat laporan } \\
\text { pelaksanaan } \\
\text { penyuluhan }\end{array}$ & 2,70 & Cukup Baik \\
\hline & Rata-rata & 2,70 & Cukup Baik \\
\hline
\end{tabular}

Sumber : Data Olahan, 2018

Tabel 2 menjelaskan bahwa hasil penelitian yang telah dilakukan mengenai kinerja penyuluh pertanian yang dilihat dari evaluasi dan pelaporan memperoleh skor rata-rata sebesar 2,70 dengan kategori "Cukup Baik". artinya, penyuluh yang ada di Kecamatan Kempas dalam melakukan evaluasi dan pelaporan dikatakan sudah cukup baik.

Indikator membuat laporan pelaksanaan penyuluhan pertanian mendapatkan skor 2,70 dengan kategori "Cukup Baik". Artinya, penyuluh yang ada di Kecamatan Kempas sebagian besar membuat laporan pelaksanaan penyuluhan dalam bentuk tulisan kemudian dilaporkan kepada atasan. Laporan pelaksanaan penyuluh yang dibuat oleh penyuluh terdiri dari laporan bulanan, laporan tri wulan, laporan semester dan laporan tahunan yang merupakan rekap dari seluruh penyuluh Kecamatan Kempas.

\subsection{Tingkat kemandirian Petani Kecamatan Kempas}

Kemandirian petani menjadi sangat penting di era global ini karena terbukanya pengaruh luar yang sangat besar terhadap produk usahatani. Dalam rangka meningkatkan daya saing terhadap produk usahataninya, maka strategi penyuluhan untuk mengembangkan sumberdaya manusia pertanian mendatang diarahkan agar mereka dapat lebih mandiri dalam melaksanakan usahataninya, yang dicirikan oleh kemampuannya dalam mengambil keputusan berusahatani secara kritis, meningkatkan efisiensi pemanfaatan sumberdaya yang dimiliki, dan meningkatkan produktivitas kerjanya.

Tabel 3 Tingkat Kemandirian Petani di Kecamatan Kempas

\begin{tabular}{|c|c|c|c|}
\hline \multirow{2}{*}{$\begin{array}{l}\text { Kemandirian } \\
\text { Petani }\end{array}$} & \multirow{2}{*}{$\begin{array}{l}\text { Rentang } \\
\text { Skor }\end{array}$} & \multicolumn{2}{|l|}{ Jumlah } \\
\hline & & Frekuensi & $\begin{array}{l}\text { Persentase } \\
(\%)\end{array}$ \\
\hline $\begin{array}{l}\text { Sangat } \\
\text { Mandiri } \\
\text { (SM) }\end{array}$ & $\begin{array}{l}4,20- \\
5,00\end{array}$ & 18 & 60,0 \\
\hline Mandiri (M) & $\begin{array}{l}3,40- \\
4,19\end{array}$ & 12 & 40,0 \\
\hline $\begin{array}{l}\text { Cukup } \\
\text { Mandiri } \\
\text { (CM) }\end{array}$ & $\begin{array}{l}2,60- \\
3,39\end{array}$ & - & - \\
\hline $\begin{array}{l}\text { Kurang } \\
\text { Mandiri }\end{array}$ & $1,80-$ & - & - \\
\hline
\end{tabular}




\begin{tabular}{|l|l|l|l|}
\hline (KM) & 2,59 & & \\
\hline $\begin{array}{l}\text { Sangat } \\
\text { Kurang } \\
\text { Mandiri } \\
\text { (SKM) }\end{array}$ & $\begin{array}{l}1,00- \\
1,79\end{array}$ & - & - \\
\hline Total & 30 & 100 \\
\hline
\end{tabular}

Sumber: Data Olahan, 2018

Berdasarkan tabel 3 diketahui bahwa tingkat kemandirian petani adalah pada kategori "Sangat Mandiri" dengan persentase 60,0\%. Jika keempat indikator kemandirian sudah dapat dilakukan petani dengan baik maka sesuai dengan penelitian Lestari (2011) akan dapat mempungaruhi tingkat kemandirian petani dalam berusahatani menjadi berada pada kategori sangat mandiri.

\subsection{Tingkat Keberdayaan Petani di Kecamatan Kempas}

Keberdayaan masyarakat adalah unsur-unsur yang memungkinkan masyarakat mampu bertahan dan mampu mengembangkan diri untuk mencapai tujuan-tujuannya. Karena itu, keberdayaan masyarakat merupakan upaya untuk terus-menerus meningkatkan harkat dan martabat lapisan masyarakat bawah yang tidak mampu melepaskan diri dari perangkap kemiskinan dan keterbelakangan. Dengan kata lain pemberdayaan masyarakat merupakan upaya untuk meningkatkan kemampuan masyarakat, mendorong keberanian agar mampu dan memiliki kemandirian dalam memilih dan alternatif perbaikan kehidupan yang lebih baik.

Tabel 4 Tingkat Keberdayaan Petani di Kecamatan Kempas

\begin{tabular}{|c|c|c|c|}
\hline \multirow{2}{*}{$\begin{array}{l}\text { Kebedayaan } \\
\text { Petani }\end{array}$} & \multirow{2}{*}{$\begin{array}{l}\text { Rentang } \\
\text { Skor }\end{array}$} & \multicolumn{2}{|l|}{ Jumlah } \\
\hline & & Frekuensi & $\begin{array}{l}\text { Persentase } \\
(\%)\end{array}$ \\
\hline $\begin{array}{l}\text { Sangat } \\
\text { Berdaya } \\
\text { (SB) }\end{array}$ & $\begin{array}{ll}4,20 & - \\
5,00 & \end{array}$ & 18 & 60,0 \\
\hline Berdaya (B) & $\begin{array}{l}3,40 \\
4,19\end{array}$ & 12 & 40,0 \\
\hline $\begin{array}{l}\text { Cukup } \\
\text { Berdaya } \\
\text { (CB) }\end{array}$ & $\begin{array}{l}2,60 \\
3,39\end{array}$ & - & - \\
\hline $\begin{array}{l}\text { Kurang } \\
\text { Berdaya } \\
\text { (KB) }\end{array}$ & $\begin{array}{l}1,80 \\
2,59\end{array}$ & - & - \\
\hline $\begin{array}{l}\text { Sangat } \\
\text { Kurang } \\
\text { Berdaya } \\
\text { (SKB) }\end{array}$ & $\begin{array}{l}1,00 \\
1,79\end{array}$ & - & - \\
\hline \multicolumn{2}{|l|}{ Total } & 30 & 100 \\
\hline
\end{tabular}

Sumber: Data Olahan, 2018

Tabel 4 menjelaskan bahwa tingkat keberdayaan petani padi swadaya di Kecamatan Kempas yang dilihat dari Sumber Daya Manusia (SDM), ekonomi produktif, dan kelembagaan masih berada pada kategori "Sangat Berdaya" yang ditunjukkan dengan persentase $60 \%$. Penyuluh sudah mampu meningkatkan keberdayaan petani seperti memotivasi petani padi untuk membentuk kelompok tani yang berguna bagi

\section{KESIMPULAN DAN SARAN}

\subsection{Kesimpulan}

Berdasarkan hasil penelitian yang telah dilakukan tentang analisis kinerja penyuluh pertanian dalam memberdayakan dan memandirikan petani padi sawah di Kelurahan Kempas Jaya Kecamatan Kempas Kabupaten Indragiri Hilir, maka diperoleh kesimpulan sebagai berikut:

1. Kinerja penyuluh pertanian di Kelurahan Kempas Jaya Kecamatan Kempas dikategorikan "Cukup Baik" dengan persentase $73,3 \%$.

2. Tingkat Keberdayaan Petani di Kelurahan Kempas Jaya Kecamatan Kempas dikategorikan "Sangat Berdaya" dengan persentase $60 \%$ dan Tingkat Kemandirian

3. Petani di Kelurahan Kempas Jaya Kecamatan Kempas dikategorikan "Sangat Mandiri" dengan persentase $60 \%$.

\subsection{Saran}

Berdasarkan hasil analisis dan kesimpulan diatas, peneliti merekomendasikan bahwa:

1. Perlunya penambahan jumlah tenaga penyuluh agar wilayah binaan untuk satu orang penyuluh tidak lebih dari satu desa, sehingga penyuluh dapat lebih fokus membina petani dalam meningkatkan keberdayaan dan kemandirian khususnya petani padi Kecamatan Kempas.

2. Penyuluh harus lebih sering mengikuti pelatihan penyuluhan terutama untuk materi terkait padi sawah sehingga penyuluh dapat menguasai masalah-masalah terkait komoditi padi. Kerja sama pemerintah juga diperlukan dalam peningkatan kegiatan penyuluhan seperti penyediaan fasilitasfasilitas yang mendukung kegiatan penyuluhan.

3. Untuk meningkatkan keberdayaan dan kemandirian petani padi sawah di Kecamatan Kempas maka kelompok tani yang diikuti harus memiliki tujuan yang jelas dan terstruktur, sehingga dengan adanya kelompok tani petani dapat mengikuti pelatihan yang dapat meningkatkan pengetahuan petani khususnya pada komoditi padi. 


\section{DAFTAR PUSTAKA}

[1] Ancok, A. 2002. Teknik Penyusunan Skala Pengukur. Pusat Studi Kependudukan dan Kebijakan Universitas Gadjah Mada. Yogyakarta

[2] Awal Maulid Sari. 2013. Kinerja Penyuluh Pertanian Dalam Pengembangan Usaha Perternakan Sapi Bali Di Kabupaten Muna Provinsi Sulawesi Utara. (unud-8311850548558-awal maulid sari tesis s2 ilmu perternakan.pdf) Diakses 5 Oktober 2017

[3] Badan Perencanaan dan Pembangunan Daerah (BAPEDA) Kabupaten Indragiri Hilir. 2017. Stastistik Sektoral Kecamatan Kempas. Indragiri Hilir

[4] Badan Pusat Statistik (BPS) Provinsi Riau. 2014. Indikator Kebutuhan Dasar Rumah Tangga Petani. Riau, Pekanbaru.

[5] Dep. Pendidikan Nasional, 2005. Kamus Besar Bahasa Indonesia, Edisi Ketiga. Balai Pustaka. Jakarta.

[6] Depertemen Pertanian. 2009. Pedoman Umum Penyuluhan Pertanian dalam Bentuk Pertauran Perundangan Tentang Jabatan Fungsional Penyuluhan Pertanian dan Angk Kreditnya. Jakarta: Badan Pengembangan Sumberdaya Manusia Pertanian. Jakarta: Depetemen Pertanian.

[7] Dinas Tanaman Pangan, Holtikulura, dan Perternakan Kabupaten Indragiri Hilir. 2015. Luas Areal dan Produktivitas Tanaman Padi Di Kecamatan Kempas. Indragiri Hilir

[8] Ismawan, Bambang. 2003. Kemandirian, Suatu Refleksi. Jurnal Ekonomi Pembangunan Th II No 3 Mei 2003.

[9] Kartasapoetra, A.G. 1994. Teknologi Penyuluhan Pertanian. Penerbit PT. Bumi Aksara, Jakarta.

[10] Leilani, Ani. 2006. Hubungan Sejumlah Karakteristik Para Penyuluh Pertanian Dengan Kinerja Mereka Dengan Pelaksanaan Tugas Pokok di Beberapa Kabupaten Provinsi Jawa Barat. Skripsi Sekolah Pascasarjana Institut Pertanian Bogor. Bogor

[11] Lestari, M. 2011. Dinamika Kelompok Dan Kemandirian Anggota Kelompok Tani Dalam Berusahatani Di Kecamatan Poncowarno Kabupaten Kebumen Propinsi Jawa Tengah. Tesis Program Pascasarjana Universitas Sebelas Maret, Surakarta.

[12] Mangkunegara, Anwar Prabu AA. 2007. Manajemen Sumber Daya Manusia Perusahaan. Bandung. Penerbit PT Remaja Rosdakarya. 